UCRL-ID-119101

\title{
A Progress Report for the Large Block Test of the Coupled Thermal-Mechanical-Hydrological-Chemical Processes
}
W. Lin
T. Buscheck
K. Lee
J. Roberts
D. G. Wilder
Y. Chang
J. Nitao
D. Ruddle
J. Blink
D. Chesnut
J. Noring
S. Sommer
P. Berge
W. Daily
M. Owens
D. Trummer
S. Blair
R. S. Glass
R. Pletcher
J. Ueng
S. Boyd
W. Glassley
A. Ramirez
J. Wagoner
V. Brugman
L. Hall
N. Rector
P. Burklund
C. Landram
T. Reitter
R.J. Glass and M. Nicholl (Sandia National Laboratories)
G. Danko (University of Nevada Reno)

\section{October 1994}

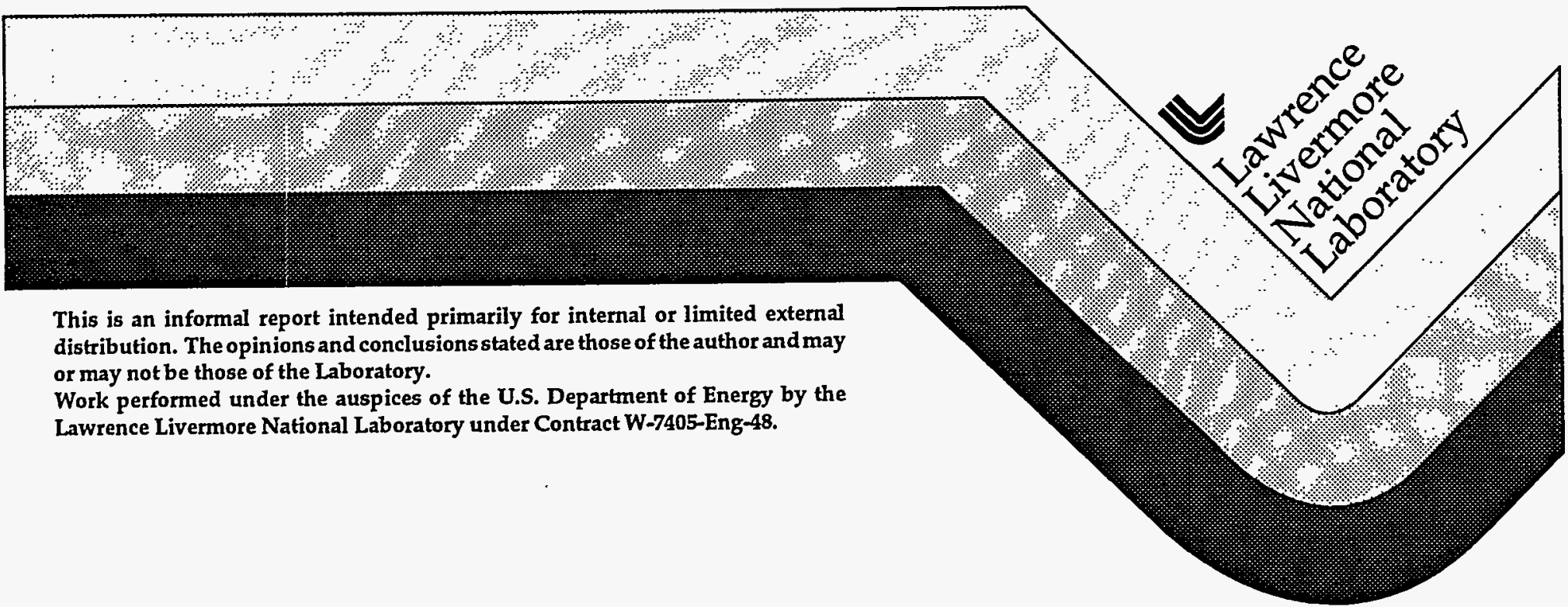
distribution. The opinions and conclusions stated are those of the author and may or may not be those of the Laboratory.

Work performed under the auspices of the U.S. Deparment of Lawrence Livermore National Laboratory under Contract W-7405-Eng-48. 


\section{DISCLAIMER}

This document was prepared as an account of work sponsored by an agency of the United States Government. Neither the United States Government nor the University of California nor any of their employees, makes any warranty, express or implied, or assumes any legal liability or responsibility for the accuracy, completeness, or usefulness of any information, apparatus, product, or process disclosed, or represents that its use would not infringe privately owned rights. Reference herein to any specific commercial product, process, or service by trade name, trademark, manufacturer, or otherwise, does not necessarily constitute or imply its endorsement, recommendation, or favoring by the United States Government or the University of California. The views and opinions of authors expressed herein do not necessarily state or reflect those of the United States Government or the University of California, and shall not be used for advertising or product endorsement purposes.

This report has been reproduced directly from the best available copy.

Available to DOE and DOE contractors from the Office of Scientific and Technical Information

P.O. Box 62, Oak Ridge, TN 37831

Prices available from (615) 576-8401, FTS 626-8401

Available to the public from the

National Technical Information Service

U.S. Department of Commerce

5285 Port Royal Rd.

Springfield, VA 22161 


\section{DISCLAIMER}

Portions of this document may be illegible in electronic image products. Images are produced from the best available original document. 


\section{Contents}

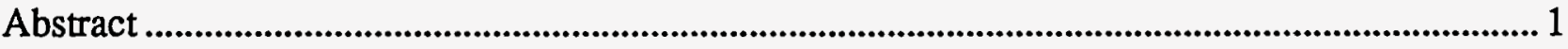

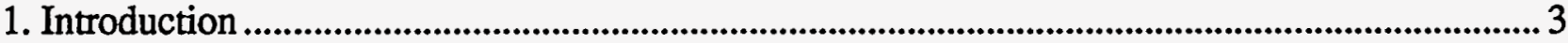

2. Description of the Tests ........................................................................................................

2.1 Small Block Tests in the Laboratory .................................................................................. 5

2.2 Test Preparations of the Large Block........................................................................... 6

2.3 Test Procedures on the Large Block .................................................................................. 6

3. Progress and Current Status ........................................................................................................ 8

3.1 Block Isolation (Activity No. LBT-01) …….................................................................... 8

3.2 Frame Construction (Activity No. LBT-02) ........................................................................ 8

3.2.1 Retrofitting the Load-Retaining Frame (Activity No. LBT-02) .......................9

3.3 Block Characterization (Activity No. LBT-03) ................................................................... 9

3.3.1 Fracture Mapping ............................................................................................. 9

3.3.2 Fracture Flow Visualization Tests ................................................................... 10

3.3.3 Vertical Boreholes.................................................................................................. 10

3.3.4 Bulk Air Permeability of the Block ....................................................................... 10

3.3.5 Neutron Logging ...................................................................................................... 11

3.3.6 Property Measurements ............................................................................................. 11

3.4 Control of Boundary Conditions (Activity No. LBT-04) ................................................... 12

3.5 Laboratory Tests on Small Blocks (Activity No. LBT-04) ………...................................... 12

3.6 Scoping Calculations (Activity No. LBT-05) .................................................................... 13

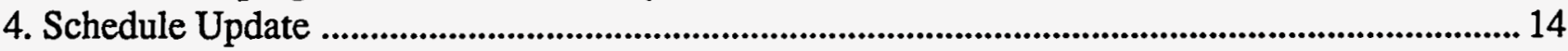

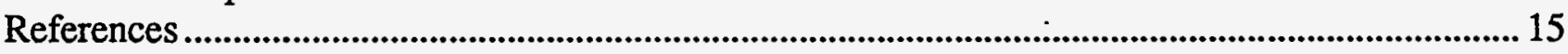




\title{
Progress Report for Large Block Test of Coupled Thermal-Mechanical-Hydrological-Chemical Processes
}

\author{
W. Lin, D. G. Wilder, J. Blink, P. Berge, S. Blair, S. Boyd, V. Brugman, P. Burklund, \\ T. Buscheck, Y. Chang, D. Chesnut, W. Daily, R. S. Glass, W. Glassley, L. Hall, C. Landram, K. \\ Lee, J. Nitao, J. Noring, M. Owens, R. Pletcher, A. Ramirez, N. Rector, T. Reitter, \\ J. Roberts, D. Ruddle, S. Sommer, D. Trummer, J. Ueng, and J. Wagoner (LLNL) \\ R. J. Glass and M. Nicholl (Sandia National Laboratories) \\ G. Danko (University of Nevada, Reno)
}

\begin{abstract}
This is a progress report on the Large Block Test (LBT) project. The purpose of the LBT is to study some of the coupled thermal-mechanical-hydrological-chemical (TMHC) processes in the near field of a nuclear waste repository under controlled boundary conditions. To do so, a large block of Topopah Spring tuff will be heated from within for about 4 to 6 months, then cooled down for about the same duration. Instruments to measure temperature, moisture content, stress, displacement, and chemical changes will be installed in three directions in the block. Meanwhile, laboratory tests will be conducted on small blocks to investigate individual thermal-mechanical, thermal-hydrological, and thermal-chemical processes. The fractures in the large block will be characterized from five exposed surfaces. The minerals on fracture surfaces will be studied before and after the test. The results from the LBT will be useful for testing and building confidence in models that will be used to predict TMHC processes in a repository. The boundary conditions to be controlled on the block include zero moisture flux and zero heat flux on the sides, constant temperature on the top, and constant stress on the outside surfaces of the block. Vapor that leaves the top will be collected. To control these boundary conditions, a loadretaining frame is required. A frame was designed to retain a stress of about $4.1 \mathrm{MPa}$, which will be applied on the surfaces of the block. The frame is under construction and will be modified later so that greater safety margins for the stress requirements can be reached.

A $3 \times 3 \times 4.5 \mathrm{~m}$ block of Topopah Spring tuff has been isolated on the outcrop at Fran Ridge, Nevada Test Site. First a belt saw was used to cut slots to isolate the block. Then a hydraulic jackhammer was used to excavate the surrounding rocks. Small blocks were collected from the rock adjacent to the large block for the tests to be conducted in the laboratory. Characterization of the large block is well under way. The fractures on the block have been mapped on the five exposed surfaces. Vertical instrument holes have been drilled. Air injection tests have been conducted in one of the vertical holes to determine the bulk permeability of the block. Pre-test model calculations indicate that a permeability of at least $10^{-15} \mathrm{~m}^{2}$ is required so that a dryout zone can be created within a practical time frame when the block is heated from within. It was determined that the large block will have enough permeability. The permeability in the block will be measured again before and after the heating tests. Neutron logging was conducted in some of the vertical holes to estimate the initial moisture content of the block. It
\end{abstract}


was found that about 60 to $80 \%$ of the pore volume of the block is saturated with water. The sawing activity did not increase the moisture content significantly, even though water was used during the sawing. Cores from the vertical holes have been used to map the fractures and to determine the properties of the rock. One of the properties that have been determined is the matrix porosity. The average porosity is about $11 \pm 2.5 \%$. Other properties (e.g., moisture retention curves, and electrical resistivity as a function of water saturation) are being measured on the cores. Other properties to be determined include stress-strain curves and mineral composition.

Model calculations are being conducted concurrently to determine test strategies, such as heating power, heating duration, and cooldown duration. A current schedule is included in the report. 


\section{Introduction}

One commonly accepted strategy in the management of high-level nuclear waste is to put it in a deep.geological repository. In the United States most high-level nuclear waste is the spent fuel retired from commercial nuclear power plants. The Yucca Mountain Site Characterization Project (YMP) investigates Yucca Mountain, Nevada, for its suitability as a potential repository for the high-level nuclear waste. The host rock at the potential repository at Yucca Mountain is the densely welded, fractured, devitrified, nonlithophysal Topopah Spring tuff. Montazer and Wilson estimated that the potential host rock has an average matrix porosity of about $14 \pm 5.5 \%$, and about $65 \%$ of its pore volume is believed to be saturated with water [1].

The major functional requirement of a nuclear waste repository is that radionuclides should not significantly contaminate the accessible environment for the life span of the repository, that is, according to federal regulations, at least 10,000 years [2]. When emplaced in a repository, the radioactive decay heat of the high-level nuclear waste will alter the thermal, mechanical, hydrological, and chemical states of the host rock. These alterations will affect the waste package environment and the near-field environment, in turn will affect the release rate of radionuclides from the waste packages and the transport of those nuclides from the near-field to the far-field environment. These alterations are coupled. For example, the thermal load will cause changes in fracture and matrix porosity of the host rock, which will affect the flow and transport of pore fluids and the potential of rock-water interactions. The thermal load will also change the mobility of the pore fluids, thereby inducing variations in the moisture content in the host rock and possibly affecting the mechanical properties of the rock and the chemical composition of the fluid. In addition, the thermal load will cause changes in the solubility of minerals in pore fluid, through dissolution and deposition, which will affect the flow and transport of the fluid and the mechanical properties of the rock. The degree of these coupled processes will depend on the thermal loading design of a repository (usually expressed in terms of mass of waste per unit area), time, and space (distance from the waste packages). For example, model analyses by Buscheck and Nitao [3] indicate that even with low thermal loading that entirely avoids boiling of pore water, heat-driven buoyant flow can dominate fluid flow in both the unsaturated and saturated zones.

The coupled thermal-mechanical-hydrological-chemical (TMHC) processes must be understood before the waste package and the near-field environments can be characterized. Characterizations of the waste package and the near-field environments are necessary for the assessment of the performance of the waste packages (source-term performance assessment) and the assessment of the performance of the total system of a repository. Experiments and tests in the laboratory and in the field are designed to understand the physics of the coupled processes. However, experiments and tests can be performed only on samples and/or regions of limited scale (from a few centimeters to tens of meters). They can only be performed in relatively short periods of time with respect to the life-span of a repository. Therefore, model calculations are necessary to extend knowledge obtained for small scales and short periods of time to predictions suitable for the repository scale and for tens of thousand of years. Before model calculations can be performed to confidently predict the waste package and near-field environments, the modelbuilding concepts must be tested.

Laboratory experiments on cores and small blocks (to a few tens of centimeters in size) provide opportunities for testing model concepts involving either intact medium or with a single fracture. Tests on a larger scale that can incorporate multiple fractures and inhomogeneities are 
needed to develop and test model concepts that deal with the coupled processes in a medium that is more representative of the potential repository horizon at Yucca Mountain.

The Large Block Test (LBT) is such test. The purpose and objectives of the LBT, and a general description of the tests, are given in SIP-NF-02, Rev. 0 [4]. A more detailed description of the test methodology, requirements, and procedures is given in an activity plan [5]. As will be described later, the LBT will provide experiments with controlled boundary conditions so that they will be more useful for testing some of the concepts of the coupled TMHC processes. The tests will be conducted in a block of Topopah Spring tuff $3 \times 3 \times 4.5 \mathrm{~m}$ in size. The block is isolated from the outcrop of Topopah Spring tuff at Fran Ridge, about $5 \mathrm{~km}$ eastern of Yucca Mountain, Nevada. The block will be heated from within to a maximum temperature of about 135 to $140^{\circ} \mathrm{C}$ by heaters located in a plane about $3 \mathrm{~m}$ from the top of the block. The temperature at the top of the block will be kept at about 60 to $80^{\circ} \mathrm{C}$; guard heaters will be used to keep the sides of the block as close to adiabatic as possible. A load of about $4 \mathrm{MPa}$ will be applied to the sides and top of the block so that its deformation will be constrained by a stress similar to the horizontal lithological overburden at the potential repository horizon. The heaters in the block will be energized for at least 4 to 6 months, followed by a cooldown period of about the same duration. The processes to be tested include dominating heat transfer mechanism, condensate refluxing, re-wetting of the dry-out zone following the cool-down of the block, deformation, and chemical variations in the water. The block will be dismantled after the tests so that the effects of heating and cooling on rock-water interaction and mechanical properties can be examined.

Meanwhile small blocks will be tested in the laboratory for individual processes such as thermalmechanical, thermal-hydrological, and thermal-chemical couplings. 


\section{Description of the Tests}

The objectives of the LBT are (1) to create a controlled experimental condition in a large block so that condensate refluxing, condensate drainage, and re-wetting of the dry-out zone can be monitored; (2) to determine the dominant heat transfer mechanism under the experimental conditions; (3) to evaluate test methodologies and instruments that may be employed in future tests at the Exploratory Study Facility (ESF); and 4) to evaluate the potential for corrosion/oxidation reactions affecting coupons of candidate waste package materials in a heated rock environment. The main purpose of conducting the tests is to examine some concepts of the thermal-hydrological model that will be used to predict the near-field environment of a highlevel nuclear waste repository and to collect data for developing models for understanding the coupled TMHC processes.

A block of the nonlithophysal Topopah Spring tuff (equivalent to the thermal-mechanical unit known as TSw2) $3 \times 3 \times 4.5 \mathrm{~m}$ in size was selected as the test medium. The reasons for conducting the tests on a large block are (1) the fractures in the test medium can be visually characterized from five exposed surfaces, (2) three-dimensional measurements can be easily achieved by having instruments arranged in three orthogonal directions, and (3) the test medium can be dismantled after the tests are completed so that the effect of the heating and cooling on the mechanical and chemical characteristics of the rock can be directly observed and evaluated. The size of the block is determined based on the fracture density in the rock mass. Visual observation on the outcrop at Fran Ridge indicates that the fracture density is greater than one fracture per 30 $\mathrm{cm}$. In a fractured rock mass only a small number of the fractures may conduct fluid flow [6]. A $3 \times 3 \times 4.5 \mathrm{~m}$ block will include enough fractures that fracture flow will be present during the tests. Pretest scoping model calculations indicate that a block of that size is big enough to accommodate a dryout zone and a condensate zone simultaneously during the tests. A larger block is certainly more desirable, but the cost of the load-retaining frame for a larger block would be prohibitive. An outcrop area at Fran Ridge was selected because it is more economical and quicker to conduct a test on the surface than underground, and because of the accessibility of the Fran Ridge site. The LBT consists of two parts: tests of individual processes in small blocks with single fractures in the laboratory, and integrated tests for the macroscopic coupled processes with multiple fractures in the large block.

\subsection{Small Block Tests in the Laboratory}

Small blocks (with sizes to about $30 \mathrm{~cm}$ ) of the rock adjacent to the large block will be machined for tests in the laboratory. The blocks may be intact, containing a saw cut, or with a natural fracture (if available). When blocks with a single saw cut are used, the aperture may be controlled by inserting gold or platinum foils of various thicknesses. The tests to be conducted include thermal-mechanical deformation, thermal fracturing, displacement across a fracture due to heating and cooling, drying and imbibition of intact and saw-cut blocks, condensation along a fracture, and condensate refluxing in a thermal gradient. In these tests the sample may be uniformly heated to elevated temperatures (e.g., to about $150^{\circ} \mathrm{C}$ ) or heated from one side so that a thermal gradient is maintained. The water that flows through the test samples will be analyzed for its chemical changes. The chemical data will be used to understand the thermal-hydrological- 
chemical coupling. The samples will be examined before and after each test for direct observation of the rock-water interactions.

\subsection{Test Preparations of the Large Block}

Figure 1 shows the block as isolated. Fractures on the block will be mapped. Instrumentation and heater holes will be drilled in the block. Figure 2 shows the current concept of the location of the instrument and heater holes and the instrument layout on the block surfaces. All of the holes will be sealed so that they do not become hydrological sinks during the tests. The techniques of sealing the holes include cement grout, grout and liner, packers, and Science Engineering Associates Membrane Insitu Sampling Technology (SEAMIST). A layer of high-temperature sealant such as RTV will be coated on the block side surfaces to minimize moisture flux away from the block during the tests. Instruments and heaters will be installed in the holes and on the surfaces. Grooves may be machined on certain locations on the block surfaces to accommodate the surface instruments, include electrodes for electrical resistivity tomography (ERT) and acoustic transducers. A thin layer of insulation material, such as Marinite, about $0.6 \mathrm{~cm}$ thick will be mounted on the vertical surfaces outside of the surface instruments. Temperature sensors, such as Resistivity Temperature Device (RTD), will be installed on both sides of insulating material to monitor the horizontal heat flux on the block surfaces. The heat flux information will be used to control the energy output of the guard heaters so that the block surfaces will be maintained as close to adiabatic condition as possible. The purpose of maintaining an adiabatic condition on the sides of the block is to make the heat flow in the block as close to onedimensional as possible. Then zones of guard heaters will be installed outside of the insulating layer. Each guard heater consists of a copper base plate with foil heaters on the outer surface. Outside of the guard heater will be a thicker (about $15 \mathrm{~cm}$ thick) layer of the same insulating material. Outside of this layer are the loading bladders, housed in steel structures. Beyond the bladders is the steel load-retaining frame. Figure 3 shows a schematic diagram of the layering structure between the block and the load-retaining frame.

There will also be ERT electrodes and acoustic transducers on top of the block. Again, these instruments will be mounted in grooves. Heat exchange tubing, about $5 \mathrm{~cm}$ in diameter, will be placed on top of the block. Water from a temperature control unit will circulate within the tubing. About 25 RTDs will be mounted outside the tubing to monitor the temperature. The temperature reading will be fed to the temperature control unit. At the steady state condition, the temperature on top of the block will be controlled at about $60^{\circ} \mathrm{C}$, while the temperature at the heaters is about $140^{\circ} \mathrm{C}$. The heat-exchange tubing will be covered by a layer of glass beads about $10 \mathrm{~cm}$ thick. The beads will allow the vapor that leaves the block to be condensed in a collecting tubing and weighed. Bladders with supporting structure will be installed on top of the layer of

glass beads. Then the dome-top of the load-retaining frame will be mounted on top of the bladder supporting structures. Figure 3 also shows a schematic diagram of the components on the top of the block.

\subsection{Test Procedures on the Large Block}

After the frame is assembled around the block, the instruments that must pass through the frame will be installed, tested and calibrated. The acquisition of ambient data will begin. These include 
the data to be collected by the acquisition system (DAS data) and the data to be collected manually (manual data). The DAS data include temperature, pore-gas pressure, relative humidity (determined by Humicap and/or resonant cavity), stress, displacement, and heater power output. Manual data include moisture content using neutron logging, electrical resistivity tomography, acoustic tomography, thermal conductivity and diffusivity using the Rapid Evaluation of $\mathrm{K}$ and Alpha (REKA) thermal probe, air permeability, and output from chemical sensors. The ambient DAS data will be collected for at least one week. During this period, at least one set of the manual data will be measured, except the air permeability, which will be measured when the bladders are pressurized. The bladders will then be pressurized in increments to about $4 \mathrm{MPa}$. During bladder pressurization the DAS data acquisition will continue. When the pressure in the bladders reaches $4 \mathrm{MPa}$ the manual data acquisition will be repeated and the air permeability will be measured. When the stress and displacement in the block indicate that the transient effect of the loading has disappeared, a set of the stress-strain curves of the block will be measured. To do that, displacements of the block will be measured as the pressure in the bladders is varied by a few tenths of a megapascal.

The peak pressure of $4 \mathrm{MPa}$ will be maintained for the remainder of the test. The heaters will be energized according to a heating schedule as shown in Fig. 4. As discussed in the Section 3.6, the initial heating phase may take about 4 months before the block will reach its steady state, at a maximum temperature of about $140^{\circ} \mathrm{C}$. During the heating phase (include initial heating and the subsequent steady state period of at least 2 months), the guard heaters will be energized so that the sides of the block are adiabatic. The temperature at the top of the block will be allowed to increase as a response to the heating process, and will then be kept at $60^{\circ} \mathrm{C}$ during heating.

DÁS data will be collected continuously at a rate of no greater than one reading per hour throughout the entire heating phase. Manual data will be collected about once per one to two weeks, and fluid will be sampled once every two weeks. At the end of the steady state period two sets of the stress-strain curves will be obtained. Air permeability will not be measured during the heating phase because air flow during the measurement might disturb the temperature field in the block. Air permeability will be measured after the block has gone through the heating and cooldown phases, so that the effect of the thermal disturbance on the air permeability can be evaluated. At the end of the steady state period, when enough data are obtained (as judged by the principal investigators), the block heaters will be turned off to start a natural cooldown phase. The data acquisition and fluid sampling rates during cooldown will be the same as during heating. When the maximum temperature in the block is decreased to $5^{\circ} \mathrm{C}$ above the ambient, the cooldown phase will be considered completed. This marks the end of the tests in the large block. At this point, a decision will be made whether to conduct other tests. If no other tests are to be conducted, the block will be dismantled so that the matrix and the fracture surfaces can be examined for evidence of rock water interactions. 


\section{Progress and Current Status}

\subsection{Block Isolation (Activity No. LBT-01)}

The block isolation work is completed. The block isolation activity included sawing four 4.8-mdeep, 3-m-long slots encompassing the block, excavating the rocks surrounding the block, collecting small blocks from the rocks adjacent to the block for laboratory tests, trimming the top of the block, and supporting the block.

A belt saw with a 5.8-m-long cutting bar was used to saw the slots at the block boundaries. The slots were $5 \mathrm{~cm}$ wide, $3 \mathrm{~m}$ long, and $4.8 \mathrm{~m}$ deep. The sawing started in early January, 1994, and was completed at the end of February, 1994. Bags of foam were inserted in the slots during sawing to keep the block from falling apart. The sawing went very smoothly. A hydraulic jackhammer was used to excavate the rocks surrounding the block. Before the excavation started, two rows of vertical holes, with spacings of about $0.7 \mathrm{~m}$, were drilled around the block as pre-split holes. The pre-split holes were to damp the vibration caused by the excavation so that it would not cause significant disturbance at the block. In addition, the block was tied down through four anchor bolts in the four holes drilled previously at the edges of the block (see Block Characterization, Sec. 3.3, for more details). During the progress of the excavation, supporting braces made of wood blocks and straps were installed on the sides of the block to keep it from falling apart. Early in the excavation, when the block was about $1 \mathrm{~m}$ in height, the top of the block was trimmed with a wire saw to make it level and smooth. During the excavation process, small blocks were collected from rocks adjacent to the block at three levels: $1.5,2.5$, and $4.0 \mathrm{~m}$ from the top of the block. Pre-split holes with spacings of about $30 \mathrm{~cm}$ were drilled. A block-splitter was used to remove small blocks from the ground. Some of the small blocks have been sent to Nevada Neanderthal, Inc. for cutting into smaller blocks under the direction of LLNL. Most of the small blocks are stored at the YMP Sample Management Facility.

\subsection{Frame Construction (Activity No. LBT-02)}

A steel load-retaining frame was designed to be installed outside of the block and to retain a 4$\mathrm{MPa}$ load to be applied on the surfaces of the block, both vertically and horizontally. The frame design was described in the Activity Plan [5]. Figure 5 shows an illustration of the frame. The frame consists of a dome and a cylindrical part. The cylindrical part is divided into three sections each consisting of four sectors. In September 1993 a contract was awarded to Aircraft Engineering Corporation (AEC), in Paramount, California, to construct the frame, as designed, at a fixed cost of $\$ 498,713$. The frame was scheduled to be delivered to Nevada Test Site (NTS) on May 15, 1994. On April 8, 1994, AEC requested that the delivery date be changed to the first week of July, 1994. The request was approved because it would not affect the schedule of the project. On May 12, 1994, AEC indicated that they need an additional $\$ 220,000$ to complete the frame construction. After negotiation for almost three months, an agreement was reached with $\mathrm{AEC}$ that the original contract price will be reduced by $\$ 110,000$; $\mathrm{AEC}$ will complete the dome and one of the three sections of the cylindrical part; LLNL will complete the welding of the other sections. The dome and the section of the cylinder that will be attached to it will be completed by November 15, 1994. 
The two sections (eight sectors total) of the cylindrical part of the frame are being welded at the LLNL welding shop. The schedule for completing the frame as originally designed is January 15, 1995.

\subsubsection{Retrofitting the Load-Retaining Frame (Activity No. LBT-02)}

When the load-retaining frame was under construction by AEC, the design of an anchor system to tie the frame down to the ground was begun. During the anchor system design it was noticed by Raytheon Services Nevada (RSN) that the allowable bolt stress used in the original frame design is much greater than the allowable bolt stress prescribed by American Institute of Steel Construction (AISC) specifications. A finite-element model was constructed to analyze the frame [7]. The analysis verified that the frame designed was not structurally adequate to retain the desired pressure of $4 \mathrm{MPa}$. The predicted stress levels in the gussets of the frame exceed the yield and ultimate strengths of the frame material. In addition, the axial loads in the bolts have small safety margins as compared to the yield and ultimate strengths of the bolt material. There is a significant vertical displacement between the bottom and top of the frame.

The finite-element analysis also suggested some retrofitting methods to reduce stresses in the gussets, increase the safety margins in the bolts, and decrease the vertical displacement of the frame. The most effective retrofitting methods are to move the bolts connecting the sectors together closer to the wall of the frame and to connect the bladder supporting structure to the inner surface of the frame. The retrofitting design will be reviewed by an independent engineering review team before the retrofitting modifications are performed. The modifications will be performed after the frame is completed. The current schedule for completing the retrofitting is February 15, 1994.

\subsection{Block Characterization (Activity No. LBT-03)}

The block characterization includes determination of properties of the rock and the characterization of the large block. The properties to be determined include porosity, permeability, moisture retention curves, initial moisture content, stress-strain curves, mineral compositions, and electrical resistivity as a function of water saturation. Among these properties, the determination of porosity, moisture retention curves, electrical resistivity as a function of water saturation, and initial moisture content have started. The others will be started next fiscal year. The characterization of the large block includes the fracture density and distribution, initial moisture content of the block, and the size and location of the block. Surveys have been done to determine the location and size of the block. Mapping of the fractures on the surfaces of the block was completed in early October of 1994 . The initial moisture content of the large block was determined by neutron logging before the excavation. These measurements are described in more detail in the following sub-sections.

\subsubsection{Fracture Mapping}

Before the isolation of the block, the fractures on the ground surface were mapped as soon as the ground was cleaned and reasonably leveled. Figure 6 shows the fracture distribution in an area about $6.1 \times 6.1 \mathrm{~m}$. The dip of the fractures was measured when possible. Based on this map and 
the dip of the fractures, the location of the large block was determined, as shown as the square in Fig. 6.

After the top of the block was trimmed, the fractures on the top surface of the block were mapped. Figure 7 shows the map of the fracture distribution on top of the block. The circles in the map are the location of the vertical boreholes, which are described later. The fracture density in Fig. 7 is much greater than that in Fig. 6, because more fractures became visible on a smooth surface.

After the excavation, the fractures on the sides are being mapped. Several sections of the support braces are removed at a time to expose about 1 to $2 \mathrm{~m}$ of the block for fracture mapping. We started the mapping from the top of the block. A scaffolding was set up around the block to assist the mapping activity. The fracture mapping was completed in the first week of October, 1994.

\subsubsection{Fracture Flow Visualization Tests}

Three tests were conducted outside of the large block to visualize flow of water in fractures. Blue dye was used to trace the flow path of water. In the first test, water was ponded on an area of about $1.5 \times 1.5 \mathrm{~m}$. Electrical resistivity tomography (ERT) images were taken during this test. In another test, episodic infiltration of water was applied to the ground surface. In the third set of tests, a saturated boundary was created on the ground surface. The distribution of the blue dye was mapped during the excavation process, so that a three-dimensional flow path of the water can be constructed. Data from these tests are being analyzed. The distribution of the blue dye will be compared with the ERT images.

\subsubsection{Vertical Boreholes}

After the determination of the boundary of the large block (as described in the first paragraph under Fracture Mapping, Sec. 3.3.1), vertical instrument holes were drilled. Figure 8 shows the location of these holes. The $\mathrm{N}$-holes are $7.6 \mathrm{~cm}$ in diameter; the $\mathrm{E}$-holes are $3.8 \mathrm{~cm}$ in diameter. These holes have a total depth of about $6.1 \mathrm{~m}$. Figure 2 shows the usage of these holes. Holes N4 to N7 are for mounting electrical resistivity tomography (ERT) electrodes. Cores were recovered from all of these holes. Fractures on the cores were determined. The cores are also used to determine properties of the rock, as described in Property Measurements, Sec. 3.3.6. Figure 9 shows one example of the fractures determined from cores in some of the holes. Borehole video images were obtained in some of these holes to observe the fractures. The fracture information of the cores and the video image of the holes will be used along with the fractures mapped on the surfaces to determine a three-dimensional picture of the fracture distribution within the block.

\subsubsection{Bulk Air Permeability of the Block}

Hole N1, as shown in Fig. 8, was the first of the vertical holes to be drilled. After N1 was drilled, air injection tests were conducted in it to determine the bulk air permeability of the block. Pretest scoping calculations indicated that a minimum bulk air permeability of about $10^{-15} \mathrm{~m}^{2}$ would be required in order to generate a dry-out zone and a condensate zone in the block within a practical time frame (e.g., a few months). Therefore, the air permeability measurement was to be used to decide if the location was suitable for the LBT. A two-packer system, with a space of about $48.3 \mathrm{~cm}$ between the packers, was used to conduct the injection tests. Each of the two packers has a seal length of $0.61 \mathrm{~m}$. A pressure of about $0.75 \mathrm{MPa}$ was used to inflate the packers. The injection pressure of the air ranged from 0.014 to $0.17 \mathrm{MPa}$. The 
measurement was conducted at various depths in the hole. Figure 10 shows the measured air permeability as a function of depth. Figure 10 indicates that most parts of the block have an air permeability greater than $10^{-15} \mathrm{~m}^{2}$. Because the permeability is measured from a single hole injection test, it is probably very sensitive to the intersection of fractures to the injection hole. The air permeability measurement will be conducted again before and after the heating of the block.

\subsubsection{Neutron Logging}

After the completion of the vertical drilling, neutron logging was performed in holes E2, E3, E4, and E9 to determine the initial moisture content in the block. The block should have at least 50\% of its pore volume saturated with water in order to have enough moisture to create a condensate zone above the heaters. The neutron logging was repeated after the sawing of the boundary slots of the block. The neutron tool was calibrated in the Hydrogen Content Test Unit at NTS. The matrix porosity of the rock, as determined from the cores, was used to reduce the neutron data to water saturation level. The determination of the matrix porosity is described in Sec. 3.3.6. Figure 11 shows the moisture content in the block as a function of depth before and after the sawing, as measured by neutron logging in hole E4, which is near the middle of the block. The results from other holes agree well with this one. As with the air permeability measurement, this was also a decision-point measurement to decide if the block contains enough moisture for the planned tests. The neutron logging will be repeated just before the beginning of the tests and during the tests to monitor the change of moisture content at various locations in the block as a function of time.

\subsubsection{Property Measurements}

The properties of the rock in the LBT that have been measured so far are matrix porosity, initial moisture content, moisture retention curves, and electrical resistivity as a function of moisture content. These are described in the following paragraphs.

Cores from the vertical holes are used to measure the matrix porosity. Two methods are used to obtain the matrix porosity: the dry/saturated density method and mercury porosimetry. The matrix porosity using the dry/saturated density method is $10.9 \pm 1.5 \%$. The average bulk matrix porosity using mercury porosimetry is $11.55 \pm 2.28 \%$, with a minimum value of $8.23 \%$ and a maximum value of $20.18 \%$. These two methods of determining porosity agree very well. There appears to be a systematic increase of porosity with depth. Preliminary results also indicate that porosity increases with increasing distance from a fracture. This variation of porosity may be caused by alteration around fractures due to water flowing through them.

Small pieces of the rock were collected at the LBT site for determining initial moisture content. They were put in sealed bags at the site and weighed immediately. They were later dried in the laboratory at LLNL, yielding a measure of the total amount of the moisture in them. They are being saturated with water so that their volume can be determined. The volume is needed to calculate the water saturation in those samples.

Small disc samples were prepared from the cores for the moisture retention curves measurement. The moisture retention as a function of suction potential in the imbibition phase at $25^{\circ} \mathrm{C}$ has been determined. The samples are in the dehydration phase of the measurement. The measurements will be continued at elevated temperatures.

The samples for measuring electrical resistivity as a function of water saturation are being prepared. No measurement has been conducted yet. 


\subsection{Control of Boundary Conditions (Activity No. LBT-04)}

The boundary conditions to be controlled include zero moisture flux (moisture barrier), zero heat flux (guard heaters), and constant stress (loading bladders) on the sides and vapor collection, temperature control, and loading bladders at the top of the block.

The moisture barrier will be a layer of high-temperature RTV and Viton sheet. Both have been used successfully in the laboratory as pressure seal at high temperature. A layer of RTV will be painted on the block surfaces, then the Viton sheet will be attached to the RTV before it is cured.

Thermal conduction calculations were conducted to design the guard heater requirement and arrangement so that the sides of the block can be kept at adiabatic conditions during the test $[8,9]$. Figure 12 shows the conceptual guard heater configuration on one side and two corners of the block. Laboratory tests to study the functioning of a guard heater assembly, including guard heaters, a copper base plate, and insulation material, are being conducted.

The design of the bladders and the bladder supporting structures are essentially completed. The bladders will be able to provide $4 \mathrm{MPa}$ load on the block. In case of a bladder failure, the bladder supporting structures are designed to keep each of the neighboring bladders from extruding into the space of the failed one. The bladder supporting structure is also designed to accommodate the displacement of the bladder wall during the loading and heating/cooling of the block. The designs will be reviewed by an independent review team.

Thermal model calculations were conducted to design a temperature control system on the top of the block [10]. It was concluded that with circulating water carried in a pipe $5 \mathrm{~cm}$ in diameter, $15 \mathrm{~cm}$ center-to center spacing, and a mass flow rate of $227 \mathrm{~g} / \mathrm{s}$, the temperatures in the circulating water and in the rock on the top of the block will not differ by more than $5^{\circ} \mathrm{C}$. The circulating water pipes will be laid on the top surface of the block. A thermal control unit to control the temperature in the circulating water has been purchased.

The space between the circulating pipes on the top of the block will be filled with glass beads. A structure to retain the glass beads on top of the block has been designed. The glass beads will serve two functions: to transmit the load from the bladders to the top of the block uniformly and to allow vapor to leave the block. Outlet pipes will be installed in the wall of the retaining structure to collect the vapor that leaves the block. Laboratory tests were conducted to verify that the compaction of the glass beads under a stress of $4 \mathrm{MPa}$ does not have significant effect on the design of the bladders.

The loading system on top of the block is similar to that on the sides of the block. Ten bladders will be used to cover the area of $3 \times 3 \mathrm{~m}$ on top of the block. Each of the bladders is also housed within a support structure.

\subsection{Laboratory Tests on Small Blocks (Activity No. LBT-04)}

Tests on small blocks in the laboratory have started. A block of about $10 \times 10 \times 2.5 \mathrm{~cm}$, with a tensile fracture, was used to test the ability of an $\mathrm{x}$-ray scanning technique to monitor fracture flow and matrix imbibition. The test will be continued.

Two blocks of about $30 \times 30 \times 60 \mathrm{~cm}$ have been machined. These blocks contain multiple intact fractures. They will be used to conduct tests of thermal-mechanical processes. 


\subsection{Scoping Calculations (Activity No. LBT-05)}

In addition to the previously mentioned thermal model calculations for designing the boundary controls, scoping model calculations of the thermal-hydrological processes in the large block have been performed. These calculations are included in a separate report, which is undergoing LLNL internal review [11]. The scoping calculations will be continued to analyze various boundary conditions and heating strategies. 


\section{Schedule Update}

A current schedule of the LBT is shown Fig. 13. Most of the schedule delays so far were due to the block excavation and the construction of the frame. 


\section{References}

[1]. Montazer, P. M., and W. E. Wilson (1984), "Conceptual hydrologic model of flow in the unsaturated zone, Yucca Mountain, Nevada," USGS-84-4345 Water Resources Investigative Report, U.S. Geol. Survey, Denver, CO. (NNA.890327.0051)

[2]. U. S. Nuclear Regulatory Commission, (1984), Disposal of High-Level Radioactive Wastes in Geological Repositories, Code of Federal Regulation, Part 60, 10CFR60, pp. 540 - 570. (readily available)

[3]. Buscheck, T.A. and J. J. Nitao, (1993) "Repository-Heat-Driven Hydrothermal Flow at Yucca Mountain, Part 1: Modeling and Analysis," Nucl. Tech., Vol. 104, pp 418 - 448. (readily available).

[4]. Lin, W., (1993), Scientific Investigation Plan for the Coupled Thermal-MechanicalHydrological-Chemical Processes, SIP-NF-02, Rev.0.,SIP-NF-02, Rev.0. (readily available)

[5]. Lin, W., (1994), Large Block Tests of Coupled Thermal-Mechanical-HydrologicalChemical Processes, Activity Plan AP-LBT-01, Rev. 0. (readily available)

[6]. Chesnut, D. A. (1992), "Characterizing the Altered Zone At Yucca Mountain: The Beginning of A Testing Strategy," High Level Radioactive Waste Management, Proceedings of the Third International Conference, Las Vegas, NV, April 12-16, 1992, American Nuclear Society, La Grange Park, IL, pp1026-1039. (NNA.920505.0062)

[7]. Lee, K. (1994), Progress Report on Pre-Test Calculations for the Large Block Test, Draft, UCRL-ID-118699, LLNL. (readily available) 


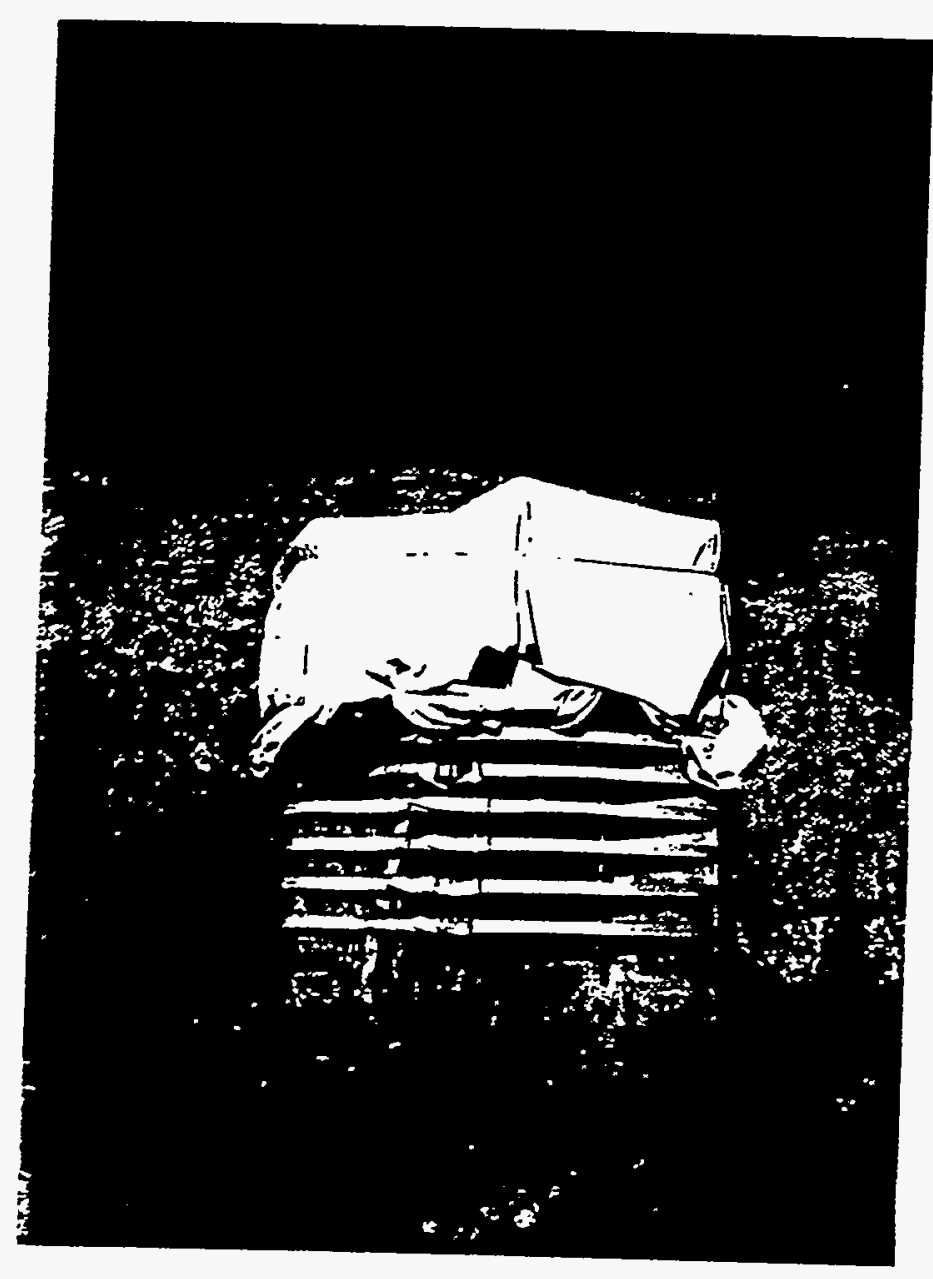

Figure 1. The $3 \times 3 \times 4.5 \mathrm{~m}$ block of Topopah Spring tuff as isolated at Fran Ridge. The protective braces are to prevent the block from the disturbance due to the excavation. The cover on the block is to reduce loosing moisture content in the block. 


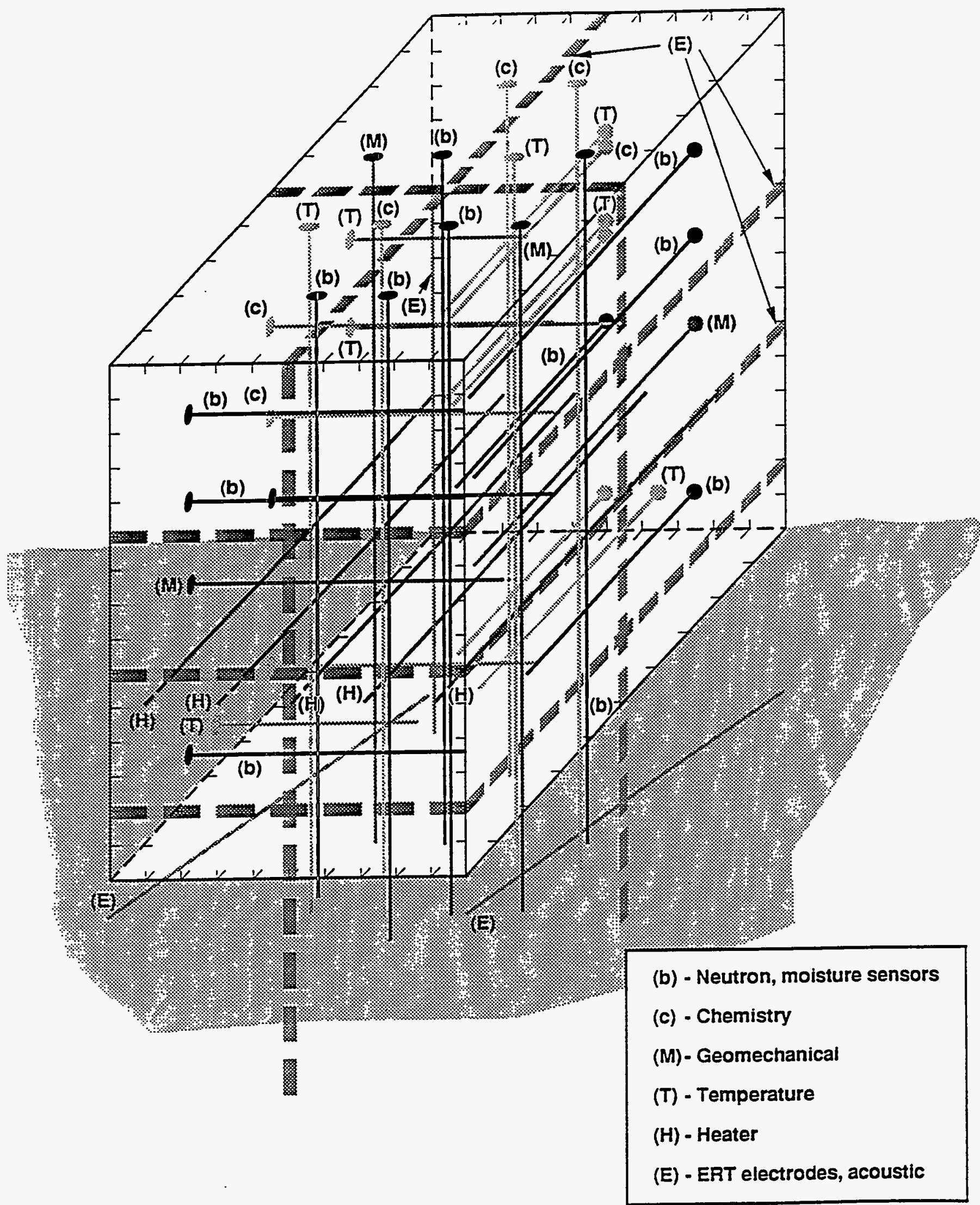

Figure 2. The configuration of the instrument and heater holes in the block and the instruments on the block surfaces. 


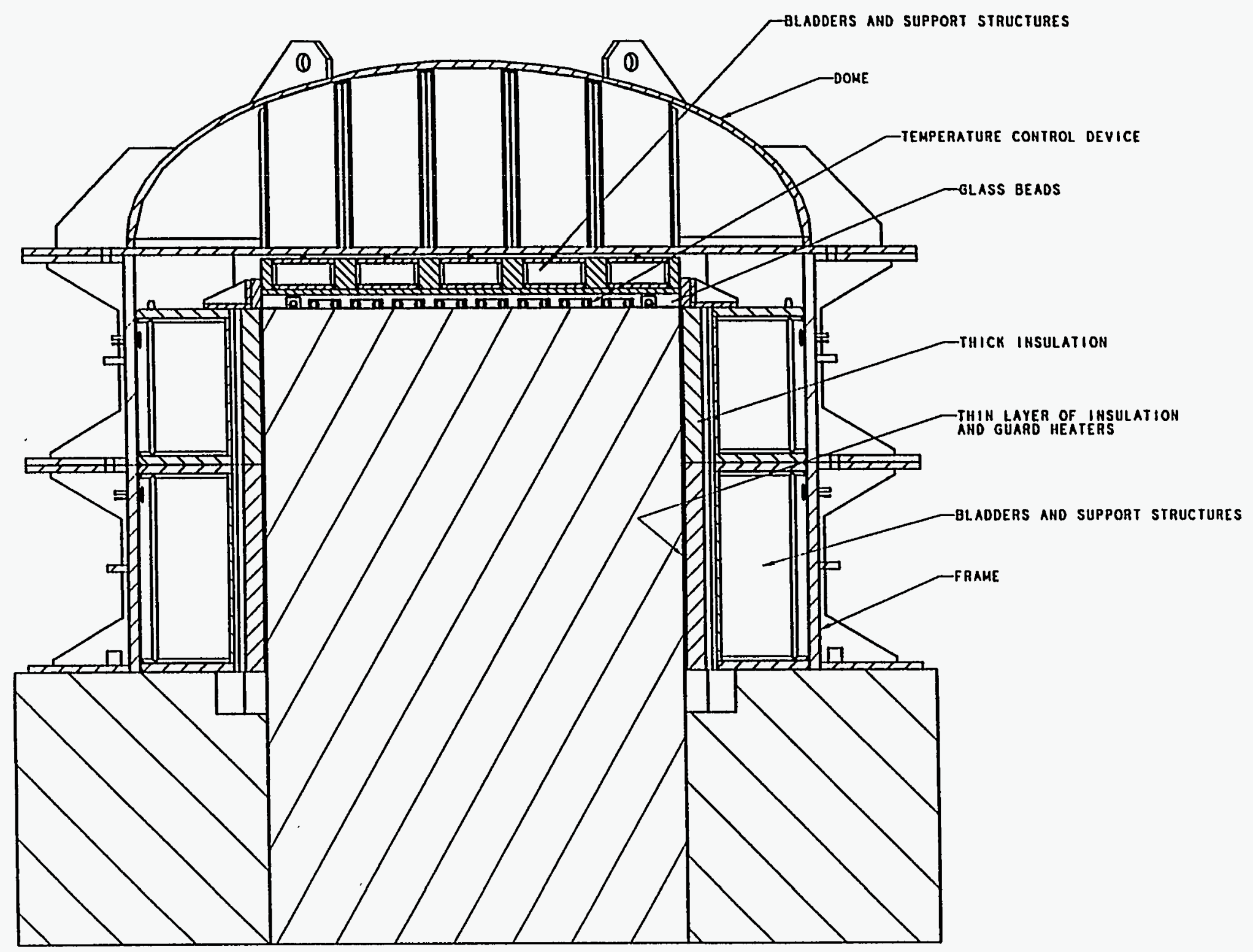

Figure 3. A schematic diagram showing the horizontal boundary control structures between the block and the frame and the vertical boundary control components on the top of the block. 
*Large Block Test, Heter Perm, Variable Power Heating*

HEATER BOREHOLE TEMPERATURES AND TOTAL HEATER POWER LEVELS

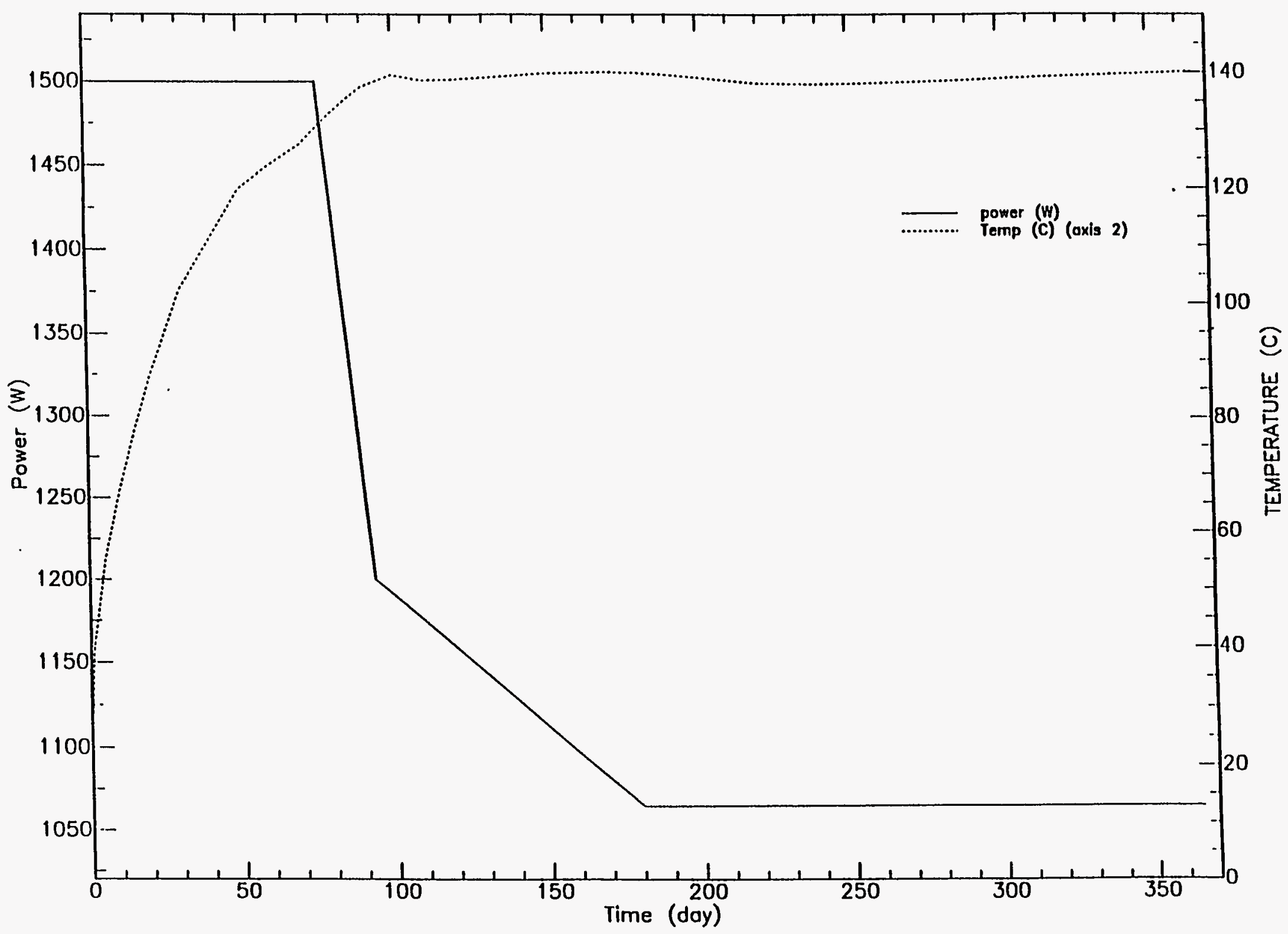

Figure 4. Heating schedule of the heaters within the block to reach a maximum steady state temperature of $140^{\circ} \mathrm{C}$. 


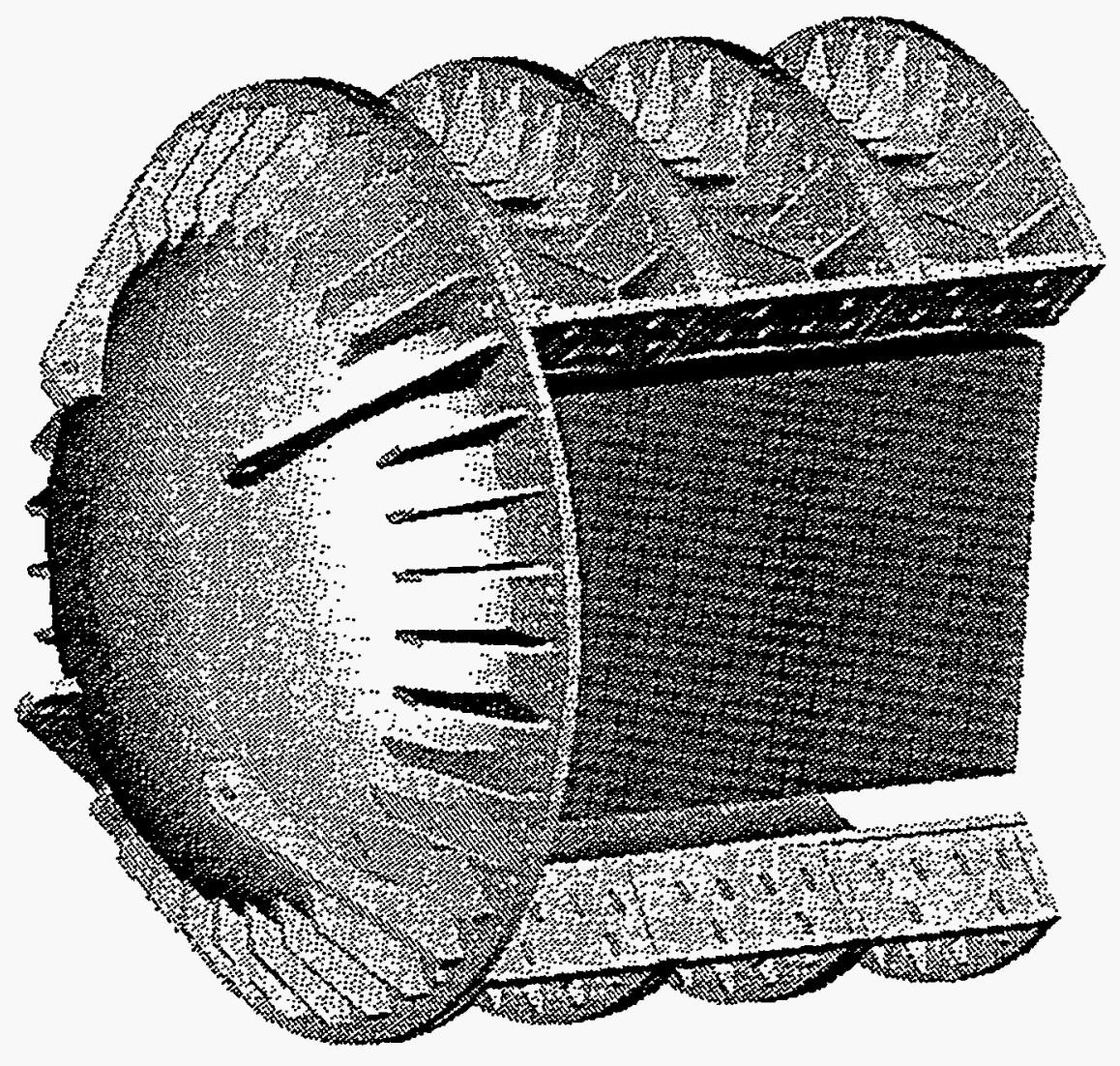

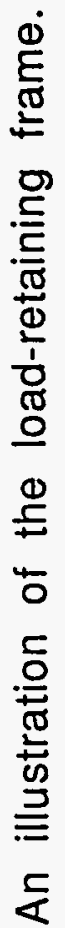

นก

递 


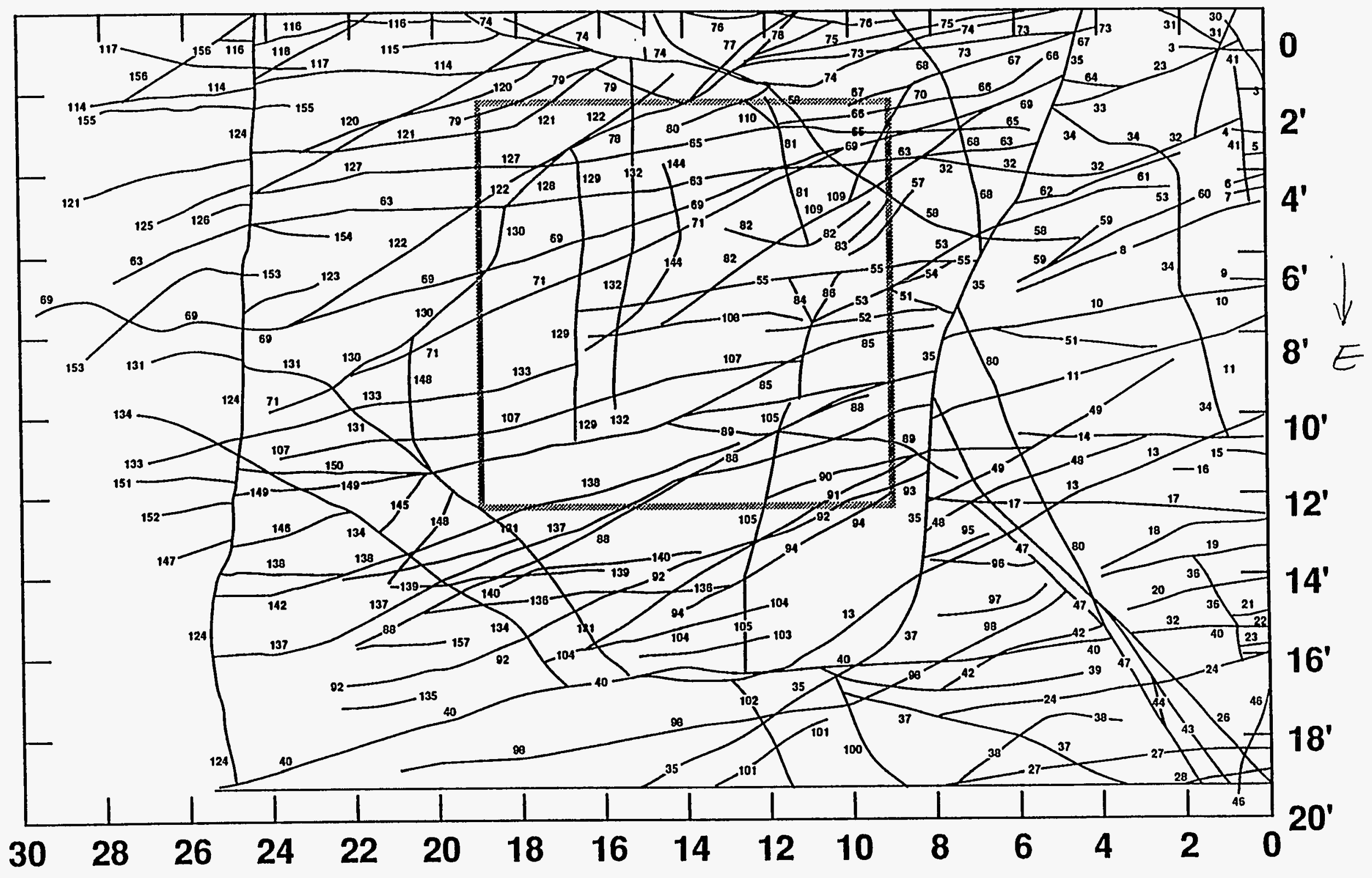

Figure 6. A map of the fractures on the ground before the sawing of the block boundary slots started. The square is the location of the large block. 


\section{Fracture and vertical borehole location map top of large block}

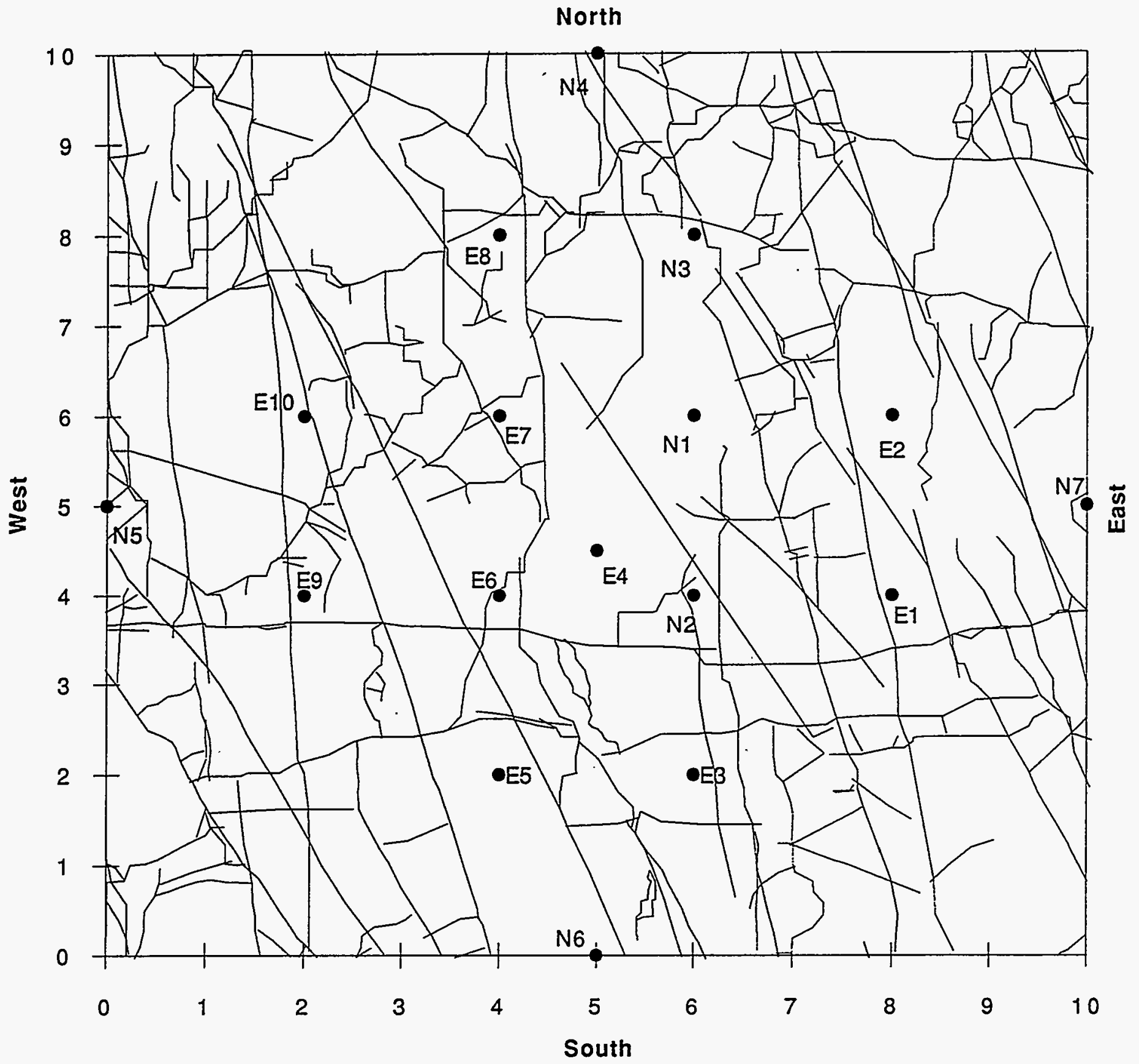

Figure 7. The fracture location map on top of the block. The circles are the location of the vertical holes. 


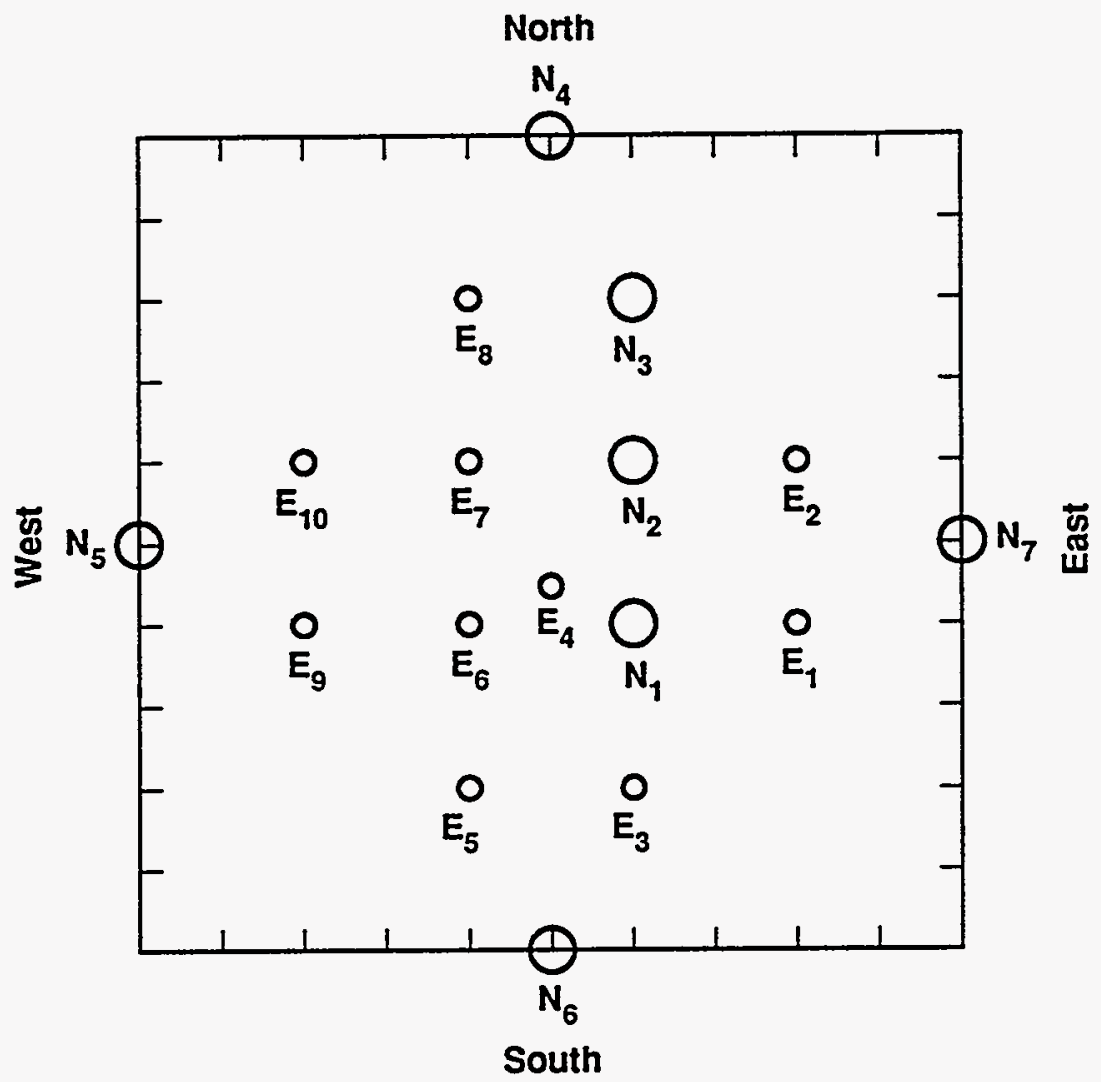

Figure 8. The location of the vertical holes drilled in the block. The $\mathrm{N}$-holes are $7.6 \mathrm{~cm}$ in diameter; the E-holes are $3.8 \mathrm{~cm}$ in diameter. $\mathrm{N} 4$ to $\mathrm{N} 7$ were drilled at the edges of the block for mounting the electrodes of ERT. 
Top of Block

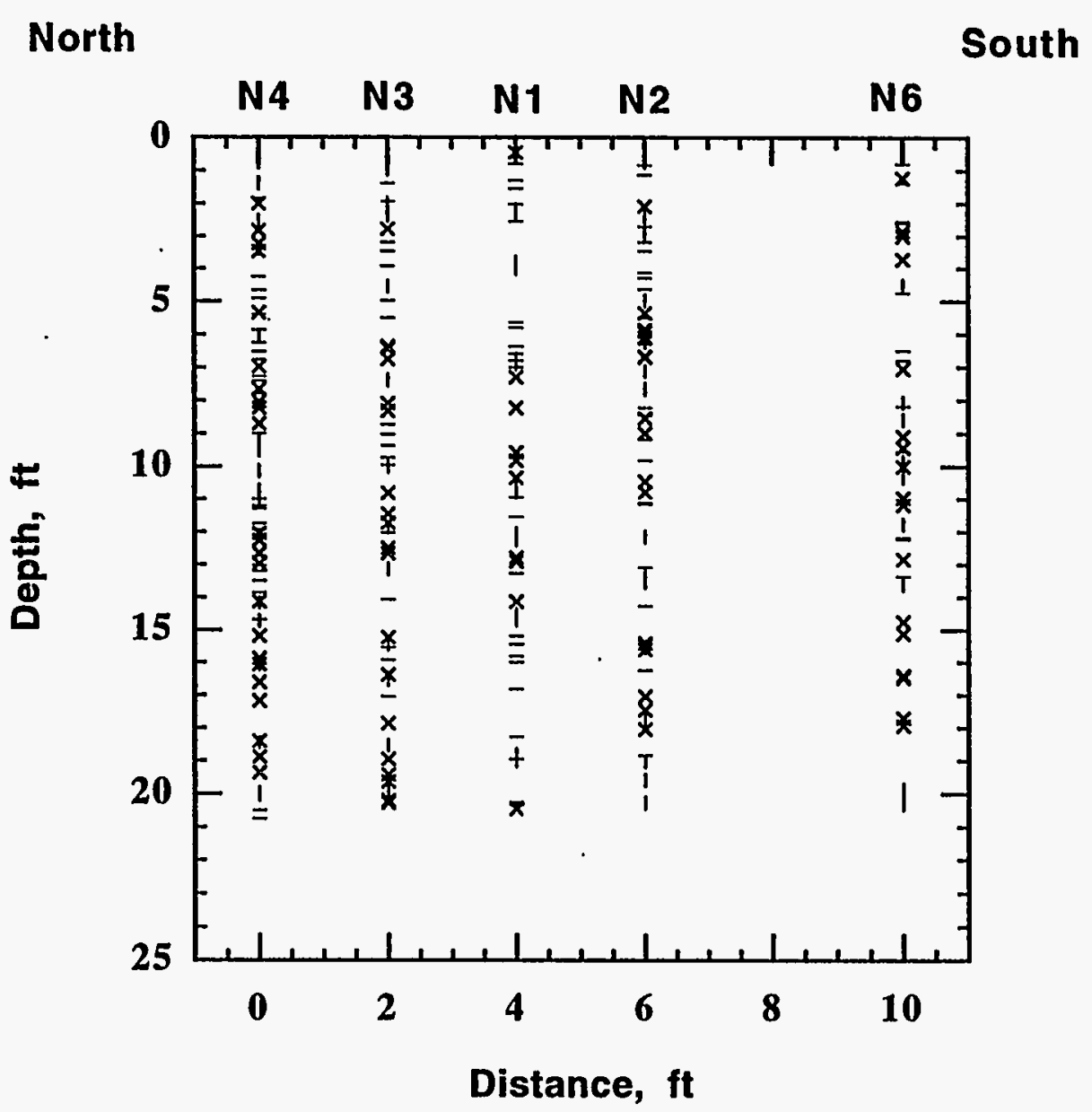

Figure 9. Fractures determined from cores of some of the vertical $\mathrm{N}$-holes. The horizontal bars represent dip angle less than $20^{\circ} ; x^{\prime} s$ represent dip angles between 20 and $70^{\circ}$; and vertical bars represent dip angles between 70 and $90^{\circ}$. 


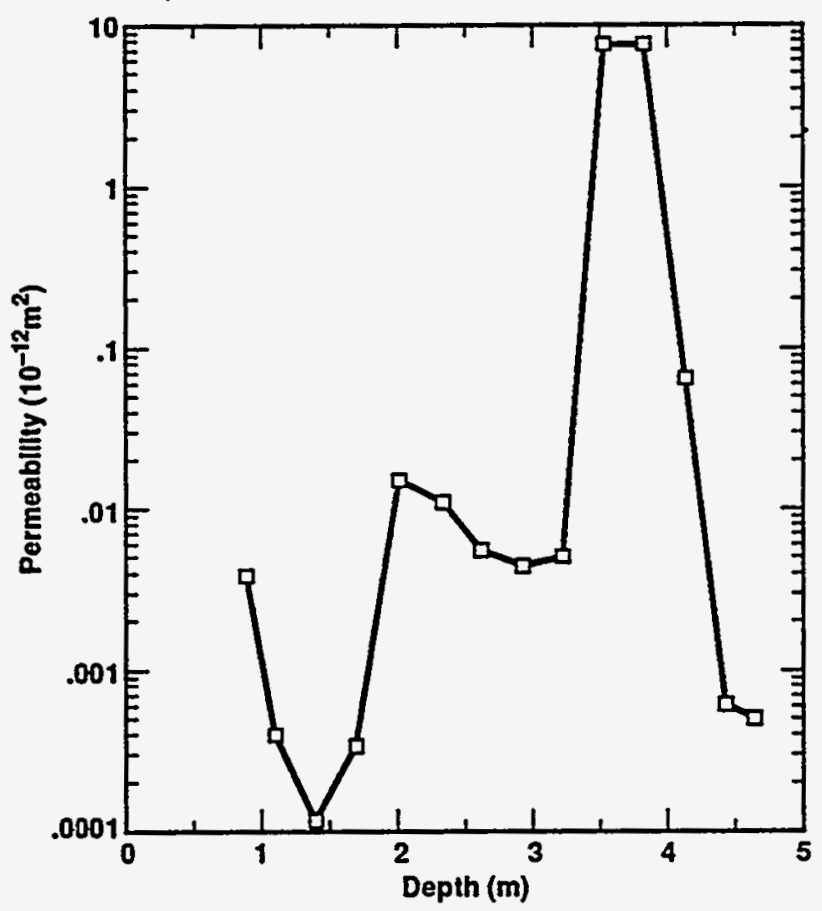

Figure 10. Air permeability of the large block as a function of depth measured from a single borehole air injection test in N1 hole 


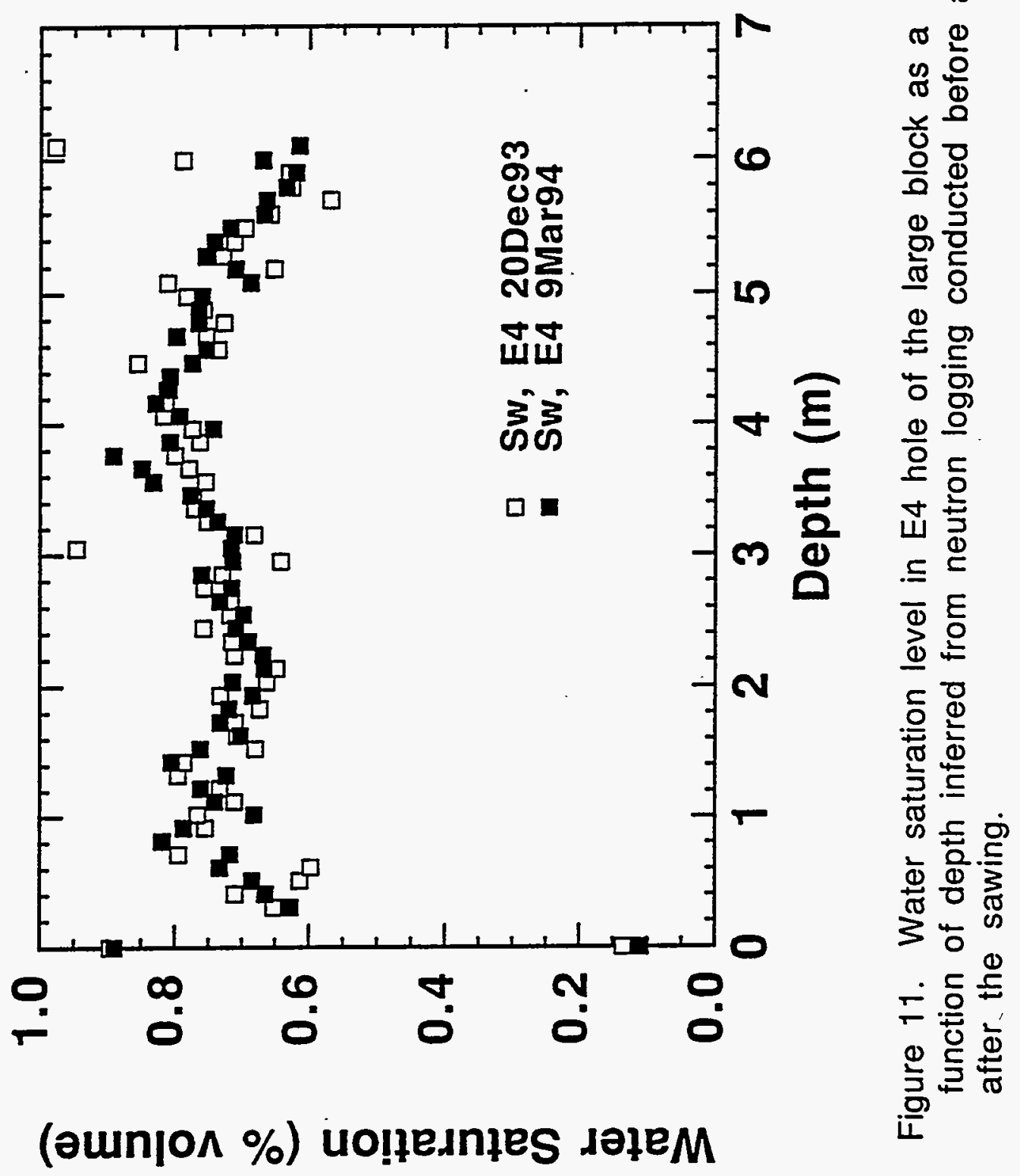




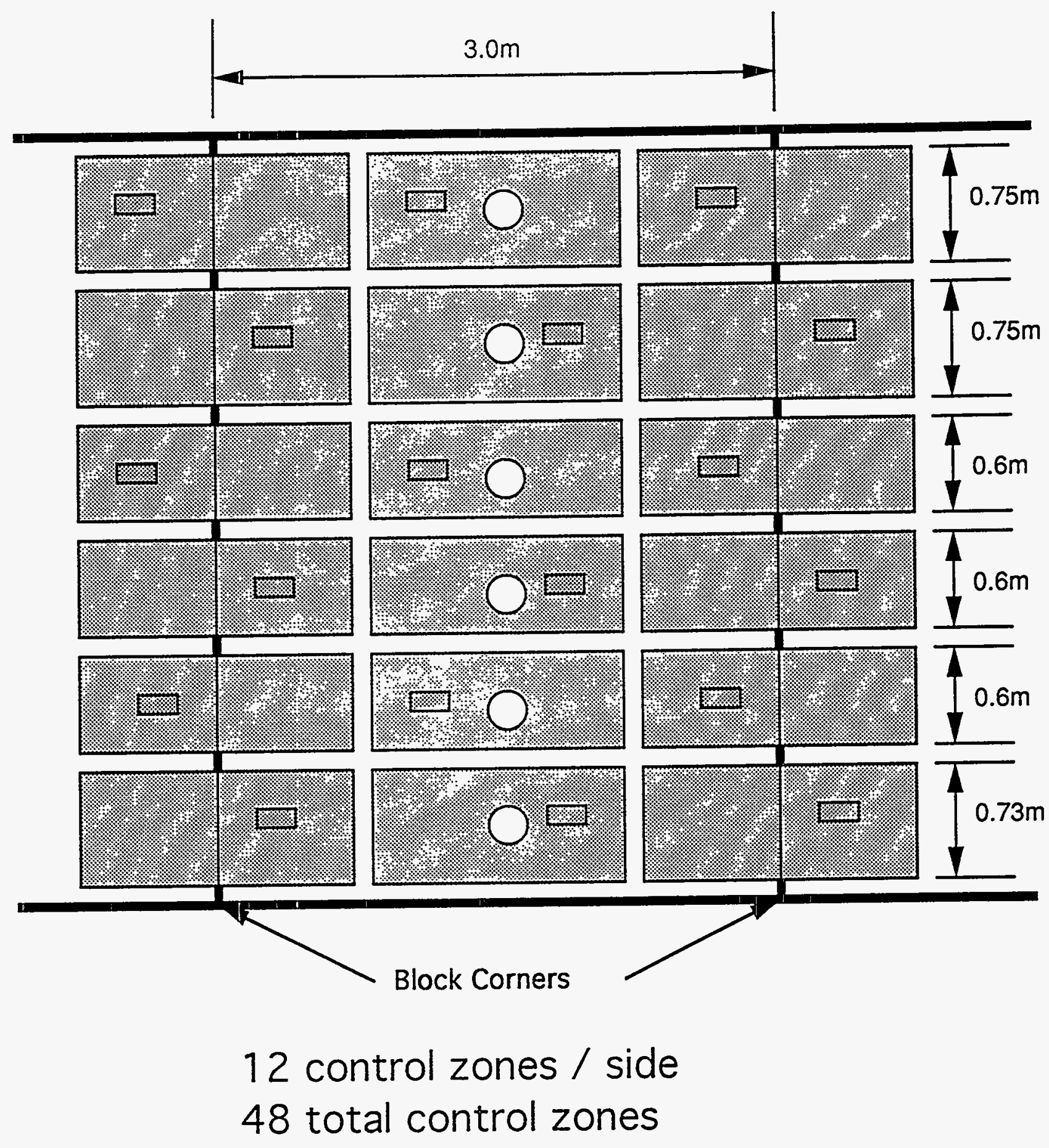

Corner copper plate zones are continuous bent sheets

Figure 12 A conceptual configuration of the arrangement of the guard heaters on one side and two corners of the block 


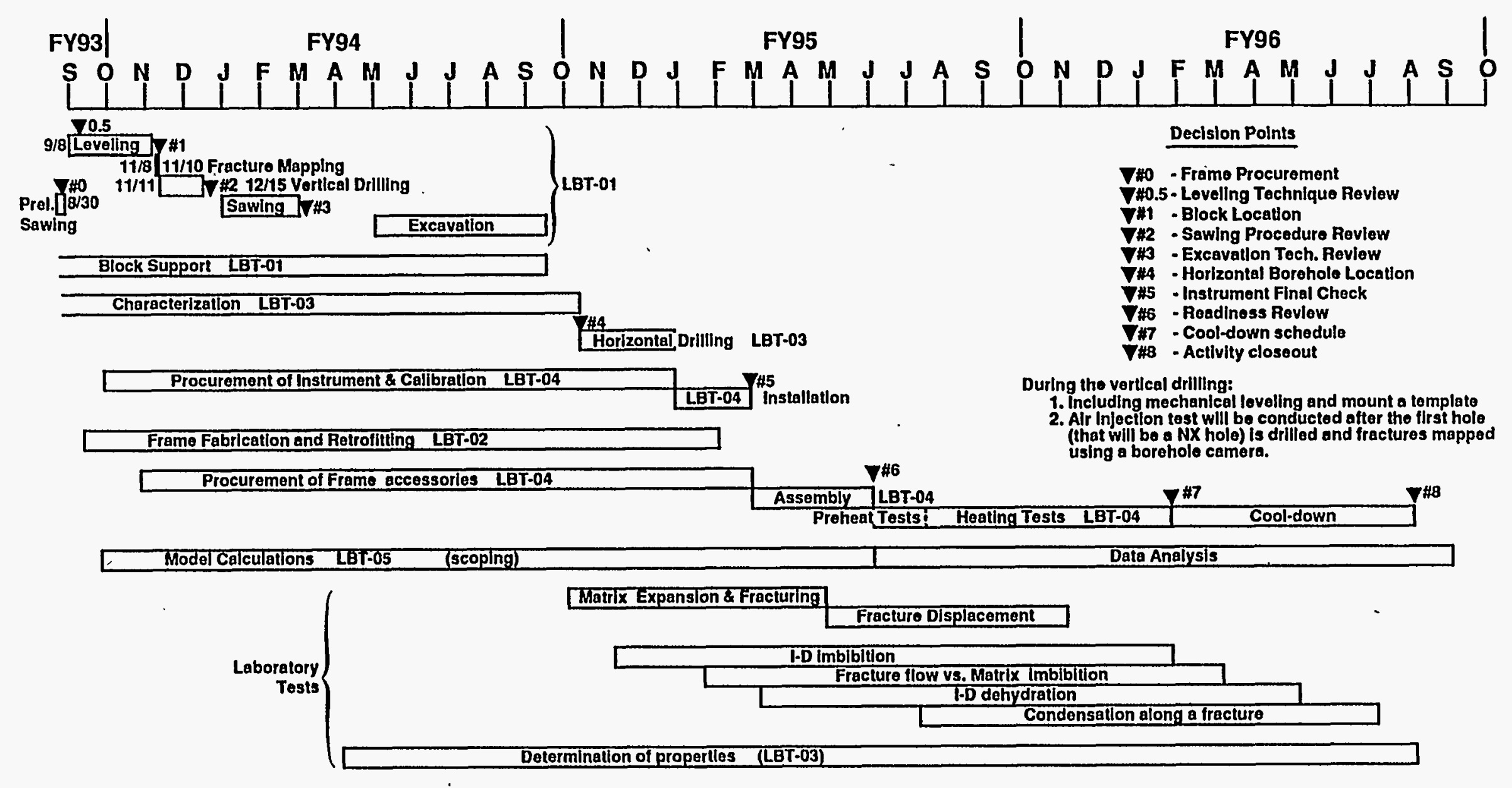

Figure 13. The current schedules of the LBT. 
The following number is for Office of Civilian Radioactive Waste Management Records Management purposes only and should not be used when ordering this document:

Accession Number: $\quad$ MOL.19950321.0056 